\title{
In Vitro Fungicide-Insensitive Profiles of Sclerotinia homoeocarpa Populations from Pennsylvania and the Surrounding Region
}

\author{
Cameron M. Stephens and John Kaminski, ${ }^{\dagger}$ Department of Plant Science, The Pennsylvania State University, University Park 16802
}

\begin{abstract}
Repeated fungicide applications are typically required to provide adequate control of dollar spot on golf courses and may shift Sclerotinia homoeocarpa populations from sensitive to insensitive or resistant to an active ingredient. The objective of this study was to characterize the geographic distribution of fungicide-insensitive, fungicide-resistant, and multiple fungicide insensitive (MFI) S. homoeocarpa populations on golf courses in Pennsylvania and the surrounding region. $S$. homoeocarpa isolates $(n=681)$ were collected from 45 different golf courses or research facilities. Each isolate was evaluated in vitro against propiconazole, iprodione, boscalid, and thiophanate-methyl using discriminatory concentrations of $0.1,1.0,1,000$, and $1,000 \mu \mathrm{g}$ of active ingredient per milliliter of PDA, respectively. Relative mycelial growth (RMG) values were used to determine sensitivity or insensitivity based on comparison

with a baseline population. Of the 681 isolates evaluated, 81,80 , and $85 \%$ exhibited reduced sensitivity to boscalid, iprodione, and propiconazole, respectively. A total of $41 \%$ of the isolates were resistant to thiophanate-methyl. Based on mean RMG of all isolates from each golf course, 16,35 , and 37 of the 45 golf courses exhibited reduced sensitivity to boscalid, iprodione, and propiconazole, respectively. A total of 585 isolates $(86 \%)$ exhibited an MFI profile in which they were insensitive or resistant to at least two fungicides evaluated. Isolates with reduced sensitivity to boscalid, iprodione, and propiconazole, but sensitive to thiophanate-methyl, were the most common phenotype within the threeMFI profile. Fungicide insensitivity and resistance to commonly used fungicides, as well as MFI profiles, were prevalent in Pennsylvania and the surrounding areas and may cause management challenges.
\end{abstract}

Dollar spot, caused by the fungal ascomycete Sclerotinia homoeocarpa F.T. Bennett, is the most ubiquitous disease in managed turfgrass systems (Couch 1995). Although cultural practices may influence disease severity, chemical management is typically required by turfgrass managers to achieve adequate control. Repeated fungicide applications act as a selection pressure on S. homoeocarpa populations and may lead to reduced field efficacy of certain active ingredients. Although there are several mechanisms involved in fungicide resistance, selection pressure is a driving force favoring the dominance of resistant isolates in managed turfgrass systems (Latin 2011). In the United States, more money is spent on fungicides aimed at controlling dollar spot than any other turfgrass disease (Vargas 2005). Not only can fungicide resistance result in increased spending on fungicides, but the loss of active ingredients owing to resistance may limit available control options for turfgrass managers.

To date, S. homoeocarpa has developed fungicide resistance to multiple chemistries from four different chemical classes including the demethylase inhibitors, dicarboximides, benzimidazoles, and heavy metal fungicides. Fungicide resistance to heavy metal fungicides was first documented in the late 1960s (Cole et al. 1968). Although these chemistries may still provide adequate control of $S$. homoeocarpa, the negative environmental impact resulted in removal of these compounds from the market. Fungicides within the benzimidazole chemical family were released in the late 1960s. Reduced field efficacy to these fungicides was reported shortly after their release, and resistance was later confirmed in an in vitro assay (Goldberg and Cole 1973; Warren et al. 1974). S. homoeocarpa developed resistance to the dicarboximides only 3 years after they were registered (Detweiler et al. 1983). Unlike the rapid development of resistance to the benzimidazoles and dicarboximides, reduced field efficacy of demethylase inhibitors (DMIs) was reported after

${ }^{\dagger}$ Corresponding author: J. Kaminski; E-mail: kaminski@psu.edu

Funding: This research was funded by the Pennsylvania State University Department of Plant Science, The Pennsylvania Turfgrass Council, The Stanley J. Zontek Fund, and Peter and Ann Tombros.

Accepted for publication 22 June 2018.

(C) 2019 The American Phytopathological Society approximately 10 years of use (Vargas et al. 1992). Since the early 1990s, field and in vitro resistance has been well documented in the DMI, dicarboximide, and benzimidazole chemical families.

Cross-resistance, which refers to an isolate or population that exhibits resistance to multiple active ingredients within a chemical family, has been observed in the three aforementioned chemical families. Cross-resistance in the DMIs was first reported in 1995, when golf courses in Michigan and Ohio exhibited reduced sensitivity to propiconazole, fenarimol, and triadimefon (Golembiewski et al. 1995). Hsiang et al. (1998) also reported a population in Ontario, Canada, that was insensitive to propiconazole, myclobutanil, and triadimefon. Cross-resistance in the benzimidazole family was quickly observed between thiophanate-methyl and benomyl and resulted in benomyl's removal from the market in the early 1990s (Warren et al. 1974). Although the mechanism of dicarboximide resistance is poorly understood, S. homoeocarpa populations exhibiting cross-resistance to iprodione and vinclozolin have been documented (Ok et al. 2011).

$S$. homoeocarpa populations exhibiting resistance to fungicides in the benzimidazole, dicarboximide, and DMI chemical families have been well documented across the midwestern and northeastern United States. However, few studies aim to determine the severity and geographic scope of multiple fungicide insensitivity (MFI) from intensively sampled populations. MFI refers to an isolate or population that has developed insensitivity to two or more fungicides belonging to different chemical families. Multiple fungicide insensitivity in turfgrass was first reported in 1983, in which an isolate of $S$. homoeocarpa exhibited insensitivity to thiophanate-methyl and iprodione (Detweiler et al. 1983). In 2008, isolates of $S$. homoeocarpa exhibiting resistance to thiophanate-methyl and reduced sensitivity to iprodione and propiconazole were characterized (Bishop et al. 2008). MFI poses a serious concern for golf course superintendents, because the loss of efficacy of multiple active ingredients across chemical families limits chemical control options, restricts rotation possibilities, and may encourage resistance or insensitivity development to other active ingredients (Latin 2011). Although multisite fungicides, biofungicides, and other site-specific fungicides have not developed resistance, there are few chemical control options for turfgrass managers experiencing reduced field efficacy. Boscalid, a succinate dehydrogenase inhibitor (SDHI), was first released to the turfgrass market in 2004. As of this writing, fungal pathogen resistance to the SDHIs has not yet been reported in turfgrass. However, SDHI resistance in other pathosystems such as Botrytis cinerea in 
grapes (Vitis vinifera), Didymella bryoniae in cucurbits (Cucurbitaceae spp.), and Alternaria alternata in pistachio (Pistacia vera) has been reported (Avenot and Michailides 2010; Avenot et al. 2008; Veloukas et al. 2013). The site-specific nature of active ingredients within this chemical class, however, warrants a closer examination and needs to be monitored for potential resistance or insensitivity development. The objectives of this study were to (i) determine the geographic scope of resistance or insensitivity of $S$. homoeocarpa isolates in vitro against boscalid, iprodione, propiconazole, and thiophanate-methyl and (ii) characterize in vitro MFI profiles of $S$. homoeocarpa populations from Pennsylvania and the surrounding region.

\section{Materials and Methods}

Sample collection. Dollar spot samples were collected from various golf courses $(n=45)$ from May 2016 to September 2017. Samples were obtained by either site visits or by samples being sent to The Pennsylvania State University (PSU). Superintendents were instructed to collect symptomatic leaf blades from different 0.93 $\mathrm{m}^{2}$ areas at various locations on their golf course. Symptomatic leaf blades were placed in coin envelopes, mailed to PSU, and prepared for pathogen isolation. Samples collected via site visits followed the same collection procedure, and $S$. homoeocarpa was isolated from individual symptomatic leaf blades. Individual leaf blades were examined under a dissecting microscope, and the host genus and species were identified. In 2017, golf courses from different regions in Pennsylvania were randomly selected, and samples were personally collected on golf course visits following the aforementioned dollar spot collection protocol. Pennsylvania was split into various regions based on areas of the state that had a high concentrations of golf courses, which were intensively sampled for this study.

Pathogen isolation. Antibiotic water agar (AWA) and potato dextrose agar (PDA) were used to isolate $S$. homoeocarpa from symptomatic leaf blades using the procedure described by Putman et al. (2010). AWA was prepared by adding $20 \mathrm{~g}$ of granular bacteriological agar (Amresco, Solon, OH) to 1 liter of deionized water. The mixture was heated on a hot plate (VWR, Radnor, PA) set to $100^{\circ} \mathrm{C}$ and stirred at 650 rotations per minute (rpm) until dissolved. The solution was autoclaved at $125^{\circ} \mathrm{C}$ for $25 \mathrm{~min}$, and after cooling to $50^{\circ} \mathrm{C}$ in a water bath (Thermo Fisher Scientific, Waltham, MA), 0.5 $\mathrm{g} /$ liter of the antibiotics penicillin $\mathrm{G}$ potassium (EMB Millipore Corporation, Billerica, MA) and streptomycin sulfate (Tokyo Chemical Industry, Portland, OR) was stirred into the cooled molten water agar (Putman et al. 2010). AWA was poured into 100- $\times 15-\mathrm{mm}$ plastic Petri plates, allowed to solidify overnight, and stored at $4{ }^{\circ} \mathrm{C}$. PDA was prepared by adding $39 \mathrm{~g}$ of granular nutrient agar (HiMedia Laboratories, Mumbai, India) to 1 liter of deionized water. The solution was heated on a hot plate to $100^{\circ} \mathrm{C}$ and stirred at $650 \mathrm{rpm}$ until completely dissolved. The PDA was autoclaved at $125^{\circ} \mathrm{C}$ for $25 \mathrm{~min}$ and allowed to cool in a water bath to $50^{\circ} \mathrm{C}$. Molten PDA was poured into $100-\times 15-\mathrm{mm}$ plastic Petri plates, allowed to solidify overnight, and stored at $4{ }^{\circ} \mathrm{C}$.

Symptomatic leaf blades were sectioned into 3- to 5-mm lengths, surface disinfested for $1 \mathrm{~min}$ in a $0.5 \%$ sodium hypochlorite solution (10\% Clorox Bleach solution), rinsed in three consecutive sterile water baths for $30 \mathrm{~s}$, and air dried on sterile filter paper (Putman et al. 2010). Once dry, surface-disinfested leaves were set on AWA and incubated at room temperature for 3 to 5 days. Isolates were identified using macroscopic and microscopic cultural characteristics as described by Bennett (1937) in conjunction with cultural descriptions by Smiley et al. (2005). A sterile microscalpel (Thermo Fisher Scientific) was used to extract a single hyphal tip from an actively growing mycelial colony and transferring it to PDA. Hyphal-tipped isolates were grown on PDA for 3 to 5 days. Once colony diameter reached $\geq 40 \mathrm{~mm}, 8$ to 104 -mm-diameter plugs were taken from the margin of the actively growing culture with a cork borer, placed in 2.0-ml microcentrifuge tubes (VWR) containing $1 \mathrm{ml}$ of sterile deionized water, and stored at $4^{\circ} \mathrm{C}$. To ensure preservation of isolates, a second storage method was followed based on Viji et al. (2004). Filter paper was cut into thin strips and autoclaved at $250^{\circ} \mathrm{C}$ for $30 \mathrm{~min}$. A single plug from the margin of an actively growing colony was transferred to PDA and surrounded by three to four strips of sterile filter paper. Isolates were incubated on the lab bench for 3 to 5 days, or until the mycelium crossed through the filter paper. Colonized filter paper was removed from the PDA using sterile forceps and allowed to air dry in unsealed $60-\mathrm{mm}$ Petri plates for 7 to 10 days. Desiccated filter paper was placed in a 2-ml microcentrifuge tube and stored at $-20^{\circ} \mathrm{C}$.

Determination of discriminatory concentrations. Ten-fold serial dilutions of fungicides were prepared in sterile deionized water using commercial formulations of propiconazole $(1-[\{2-(2,4-$ dichlorophenyl)-4-propyl-1,3-dioxolan-2-yl \}methyl]-1 $H$-1,2,4-triazole) (Banner Maxx, Syngenta Crop Protection, Greensboro, NC), iprodione (3-[3,5-dichlorophenyl]- $N$-[1-methylethyl]-2,4-dioxo-1imidazolidinecarboxamide) (Chipco 26GT, Bayer Environmental Science, Kansas City, MO), and boscalid (3-pyridinecarboxamide, 2-chloro- $N$-[4'-chloro $\left\{1,1^{\prime}\right.$-biphenyl $\}$-2-yl]) (Emerald, BASF, Research Triangle Park, NC). Owing to the qualitative nature of $S$. homoeocarpa resistance to thiophanate-methyl (dimethyl $4,4^{\prime}$ [o-phenylene]bis[3-thioallophanate]) (Cleary's 3336, Nufarm Americas, Alsip, IL), a single discriminatory dose of $1,000 \mu \mathrm{g}$ of active ingredient (a.i.)/ml of PDA was used for in vitro fungicide assays (Jo et al. 2006, 2008; Koch et al. 2009; Ok et al. 2011; Putman et al. 2010). Ten-fold fungicide concentrations for propiconazole, iprodione, and boscalid ranged from 10 to 0.001 , from 100 to 0.01 , and from 1,000 to $1 \mu \mathrm{g}$ of a.i./ml, respectively (Jo et al. 2006, 2008; Ok et al. 2011). Fungicides were diluted in sterile deionized water to desired concentrations (Putman et al. 2010). PDA cooled to $50^{\circ} \mathrm{C}$ was stirred at $650 \mathrm{rpm}$ while $1 \mathrm{ml}$ of prepared fungicide dilution was added. Propiconazole, iprodione, and boscalid fungicideamended PDA media were poured into 100-mm Petri plates, whereas thiophanate-methyl fungicide-amended PDA medium was poured into $60-\mathrm{mm}$ Petri plates. All media were allowed to solidify for $24 \mathrm{~h}$ prior to use, and all media were used within $30 \mathrm{~h}$ of preparation.

An initial in vitro fungicide assay of 101 isolates from 11 different locations was used to determine the discriminatory concentrations of each fungicide. The final fungicides (concentrations) used for the initial experiment were propiconazole $(10,1,0.1,0.01$, and $0.001 \mu \mathrm{g}$ of a.i./ml of PDA), iprodione (100, 10, 1, 0.1, and $0.01 \mu \mathrm{g}$ of a.i./ml of PDA), and boscalid (1,000, 100, 10, and $1 \mu \mathrm{g}$ of a.i./ml of PDA). The experiment was a completely randomized design with four replications. Isolates were removed from storage and grown on PDA for 3 to 5 days prior to evaluation. For each isolate, a 4-mm-diameter plug was removed from the margin of the actively growing colony and set mycelium side down on fungicide-amended PDA. Nonamended PDA served as the control. Plates were sealed with Parafilm and incubated on the lab bench at $23 \pm 2^{\circ} \mathrm{C}$ for $48 \mathrm{~h}$, at which point the colony diameter was measured in two perpendicular directions using a ruler (Putman et al. 2010). Colony diameters of each experimental unit were averaged for data analyses. The fungicide concentration resulting in a $50 \%$ inhibition of growth $\left(\mathrm{EC}_{50}\right)$ was determined for each isolate against propiconazole, boscalid, and iprodione using the PROBIT procedure in SAS version 9.4 (SAS Institute, Cary, NC) (Miller et al. 2002). Fungicide concentration data were $\log _{10}$ transformed prior to running the PROBIT procedure, and values resulting in a 0.5 probability in the probit analysis on $\log _{10}$ (concentration) were determined to be the $\mathrm{EC}_{50}$ for each isolate. Relative mycelial growth (RMG) also was calculated by dividing the average colony diameter on amended media by the average colony diameter on nonamended media multiplied by 100 (Jo et al. 2006). Using the regression (REG) procedure in SAS, the $\log _{10}$ transformations of $\mathrm{EC}_{50}$ values were regressed against RMG at each concentration per fungicide across all experimental runs (Putman et al. 2010). Fungicide concentrations that yielded the highest coefficient of determination $\left(r^{2}\right)$ were set to be the discriminatory concentration for each active ingredient.

Sensitivity screening. Isolates $(n=681)$ from Pennsylvania and the surrounding region were screened in vitro against propiconazole $(0.1 \mu \mathrm{g}$ of a.i./ml of PDA), iprodione (1.0 $\mu \mathrm{g}$ of a.i./ml of PDA), boscalid (1,000 $\mu \mathrm{g}$ of a.i./ml of PDA), and thiophanate-methyl 
(1,000 $\mu \mathrm{g}$ of a.i./ml of PDA) using the determined discriminatory concentrations. Media preparation, plating, incubation, and data collection protocols were conducted as previously described. The estimated $\mathrm{EC}_{50}$ and $\mathrm{RMG}$ values were determined for each isolate evaluated against propiconazole, iprodione, and boscalid. Resistance to thiophanate-methyl was scored $24 \mathrm{~h}$ after incubation for the presence or absence of mycelium growth on thiophanate-methylamended PDA. RMG values were determined for isolates individually and grouped by golf course and management site (i.e., green, tee, fairway, and rough). Isolates $(n=16)$ from the Vineyard Golf Club (VGC, Martha's Vineyard, MA), which has never been sprayed with a synthetic fungicide, served as the baseline population for sensitivity. Biological amendments, plant protectants, and cultural practices are commonly used at this location for dollar spot suppression. Relative mycelial growth values were subjected to analysis of variance using the MIXED procedure in SAS version 9.4. Mean RMG values for individual isolates and groupings were compared with the baseline population from the VGC and separated at $P<0.05$ according to Fisher's protected least significant difference test.

\section{Results}

Isolate collection. A total of $681 \mathrm{~S}$. homoeocarpa isolates were collected from 45 different golf courses and research facilities from Pennsylvania and the surrounding region (Fig. 1). Within the sample collection, 147 individual populations from unique $0.93-\mathrm{m}^{2}$ areas were represented. S. homoeocarpa was isolated from cool-season hosts from different management sites (i.e., greens, tees, fairways, and roughs) throughout each location. Isolates $(n=16)$ collected from the VGC served as the baseline population.

Discriminatory concentrations. Isolates $(n=101)$ were screened in vitro on fungicide-amended PDA using 10-fold serial dilutions of propiconazole, iprodione, and boscalid. Probit transformation analysis was used to determine the $\mathrm{EC}_{50}$ and $\log \mathrm{EC}_{50}$ for each isolate. Discriminatory concentrations were determined to be $1,000 \mu \mathrm{g}$ of a.i. $/ \mathrm{ml}$ of PDA $\left(r^{2}=0.7540 ; P<0.0001\right), 0.1 \mu \mathrm{g}$ of a.i./ml of PDA $\left(r^{2}=\right.$ 0.9204; $P<0.0001)$, and $1.0 \mu \mathrm{g}$ of a.i./ml of PDA $\left(r^{2}=0.5173\right.$; $P<0.0001)$ for boscalid, propiconazole, and iprodione, respectively (Fig. 2). The relationship between $\log \mathrm{EC}_{50}$ at each discriminatory dose for individual fungicides and RMG $\left(r^{2}\right.$ values of 0.5173 to 0.9204 ) indicated that RMG could be used as a measure of fungicide insensitivity (Fig. 2).

In vitro sensitivity screening. Isolates from the baseline population at VGC had an average RMG of 43.67, 31.25, and 33.68 for boscalid, propiconazole, and iprodione, respectively (Table 1). When isolates were averaged across each golf course, a total of 37,35 , and 16 of the 45 golf courses were determined to have isolates insensitive to propiconazole, iprodione, and boscalid, respectively, when compared with VGC (Fig. 3). Thiophanate-methyl resistant isolates were found at 38 of the 45 golf courses evaluated (Table 2). Of the 681 isolates evaluated, $41 \%$ were resistant to thiophanate-methyl (Table 2). A total of 85,80 , and $81 \%$ of isolates exhibited reduced sensitivity to propiconazole, iprodione, and boscalid, respectively, when compared with isolates from VGC. With one exception, all isolates collected from fairways, greens, tees, and roughs exhibited higher RMG values when compared with VGC (Table 1). RMG of isolates collected from the roughs of golf courses, however, were similar to the baseline population when grown on boscalid-amended media. Isolates sampled from fairways, tees, and greens generally had the highest RMG.

Across all regions, mean RMG ranged from 43.67 to $56.49,30.53$ to 86.33 , and 31.25 to 89.33 for boscalid, iprodione, and propiconazole, respectively (Table 3 ). When compared with the baseline

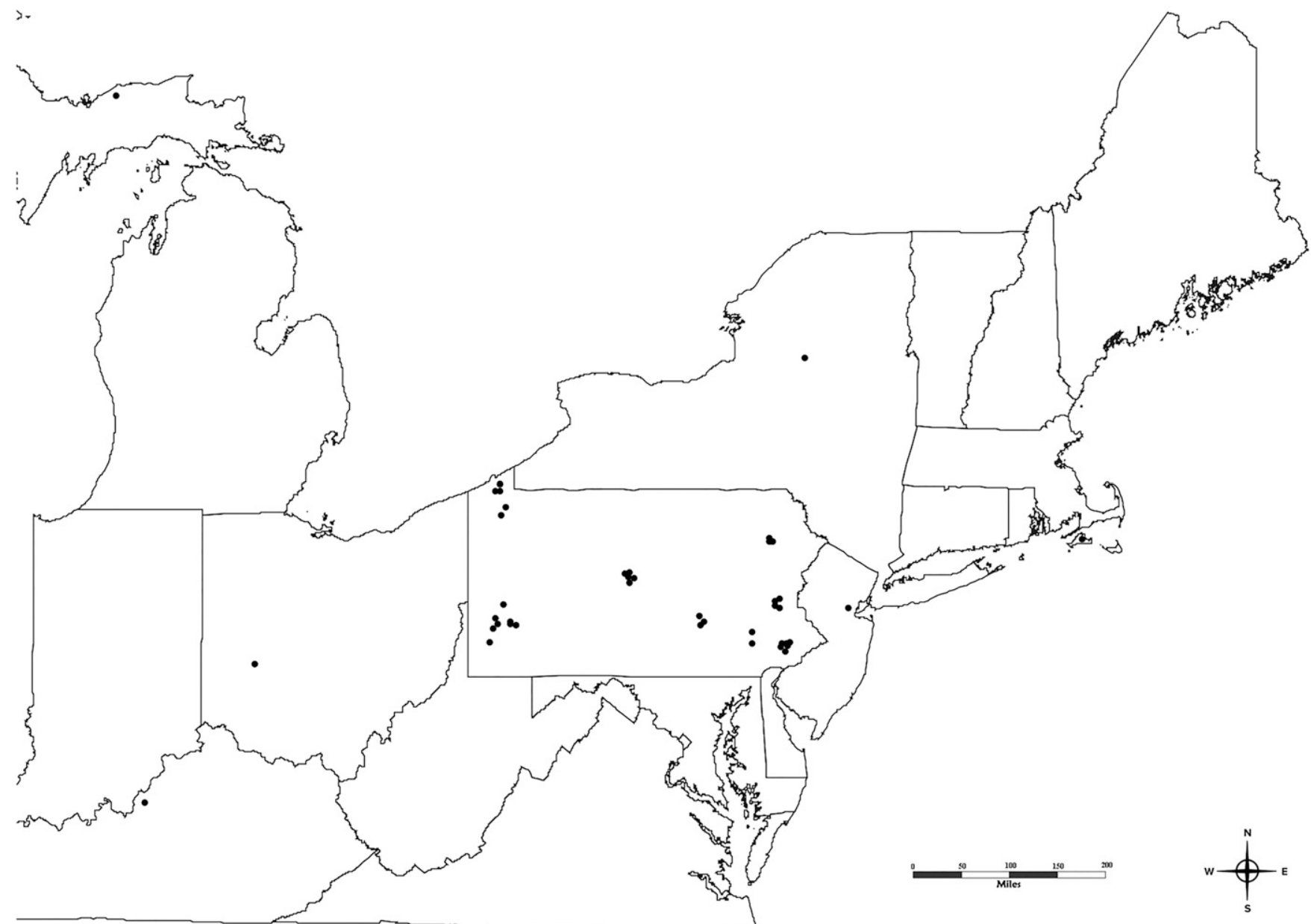

Fig. 1. Individual golf courses $(-)$ throughout Pennsylvania $(n=40)$ where Sclerotinia homoeocarpa were sampled. Samples were also collected from locations in Ohio, New York, New Jersey, Kentucky, and Michigan. 
population, regions with reduced sensitivity from the 12 regions were observed for boscalid $(n=7)$, iprodione $(n=9)$, and propiconazole $(n=11)$. For thiophanate-methyl, no resistant isolates were found in the baseline population or isolates from Michigan $(n=1)$ or New York $(n=1)$. All other regions had 22 to $91 \%$ of the collected isolates exhibiting resistance to thiophanate-methyl (Table 4).

Isolates from five golf courses had populations that were sensitive to propiconazole, iprodione, and boscalid (Fig. 3). Of these five golf courses, three (BCC, DRGC, and NMU; abbreviations in Table 2) had $S$. homoeocarpa isolates sensitive to thiophanate-methyl. Golf courses exhibiting reduced sensitivity to boscalid had as high as

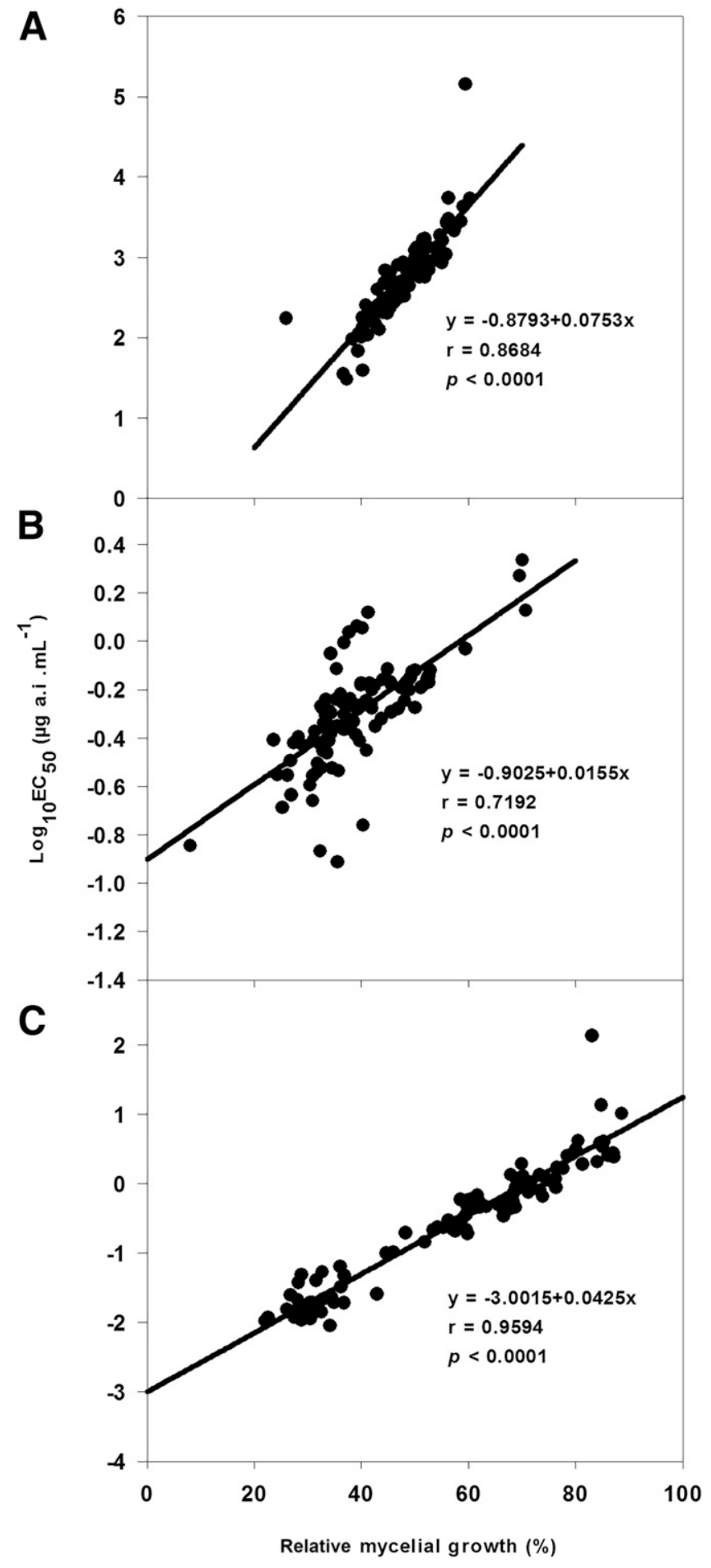

Fig. 2. Relationship between $\log E \mathrm{C}_{50}$ values and relative mycelial growth of Sclerotinia homoeocarpa isolates grown on boscalid (A), iprodione (B), and propiconazole (C) amended media at $1,000,1.0$, and $1 \mu \mathrm{g}$ of a.i. $/ \mathrm{ml}$, respectively. $\mathrm{EC}_{50}=$ fungicide concentration resulting in a $50 \%$ inhibition of growth.
49\% greater mean RMG when compared with the VGC (Table 2). For iprodione and propiconazole, the golf courses with the most insensitive isolates (PCRC and CCC) had as high as 286 and $203 \%$ greater RMG when compared with the VGC, respectively (Table 2).

Of the 681 isolates evaluated in this study, 585 exhibited an MFI profile, with 226 exhibiting a four-MFI profile (Fig. 4). Isolates exhibiting a three-MFI profile that displayed a reduced sensitivity to boscalid, propiconazole, and iprodione but that were sensitive to thiophanate-methyl represented the largest $(n=280)$ phenotype (Fig. 4). Only 79 isolates portrayed a two-MFI profile, and isolates exhibiting a reduced sensitivity to propiconazole and boscalid represented the majority ( $n=36$ ) of two-MFI combinations (Fig. 4). $S$. homoeocarpa isolates exhibiting resistance or insensitivity to one ( $n=55$ ) or no fungicides $(n=41)$ were observed in low numbers (Fig. 4). Isolates within these profiles did not follow an obvious pattern and were isolated from various management sites and golf courses. Isolates resistant $(n=400)$ and sensitive $(n=281)$ to thiophanatemethyl exhibited varying levels of sensitivity to boscalid, iprodione, and propiconazole (Fig. 5). A large number of isolates sensitive to thiophanate-methyl exhibited increased sensitivity to boscalid, iprodione, and propiconazole compared with isolates resistant to thiophanate-methyl (Fig. 5).

\section{Discussion}

The use of discriminatory concentrations proved to be an effective method for evaluating a large number of isolates in an in vitro fungicide sensitivity assay. Although associations between reduced field efficacy and in vitro insensitivity were not evaluated in this study, comparing in vitro results from a population exposed to fungicides to a baseline population that has no prior synthetic fungicide exposure was a useful technique to study $S$. homoeocarpa population dynamics. In this study, the baseline population from the VGC consistently exhibited the lowest RMG values across individual isolates, golf courses, and regions.

Table 1. Relative mycelial growth of Sclerotinia homoeocarpa after $48 \mathrm{~h}$ of incubation on fungicide-amended potato dextrose agar at discriminatory concentrations for each fungicide

\begin{tabular}{|c|c|c|c|c|}
\hline \multirow[b]{2}{*}{ Active ingredient ${ }^{v}$} & \multirow[b]{2}{*}{ Management sitew } & \multirow[b]{2}{*}{$n$} & \multicolumn{2}{|c|}{$\begin{array}{l}\text { Relative mycelial } \\
\text { growth }(\%)^{\mathbf{x}}\end{array}$} \\
\hline & & & Mean & Range \\
\hline \multirow[t]{5}{*}{ Boscalid } & Fairway & 223 & $51.15 \mathrm{ab}^{\mathrm{y}}$ & $27.80-85.07$ \\
\hline & Green & 84 & $52.80 \mathrm{a}$ & $34.35-79.86$ \\
\hline & Rough & 196 & $44.65 \mathrm{c}$ & $27.84-75.00$ \\
\hline & Tee & 162 & $49.88 \mathrm{~b}$ & $26.55-75.52$ \\
\hline & $\mathrm{VGC}^{\mathrm{z}}$ & 16 & $43.67 \mathrm{c}$ & $35.30-53.73$ \\
\hline \multirow[t]{5}{*}{ Iprodione } & Fairway & 223 & $66.44 \mathrm{a}$ & $19.62-100$ \\
\hline & Green & 84 & $67.64 \mathrm{a}$ & $24.54-100$ \\
\hline & Rough & 196 & $51.65 \mathrm{~b}$ & $20.12-100$ \\
\hline & Tee & 162 & $69.07 \mathrm{a}$ & $24.66-100$ \\
\hline & VGC & 16 & $33.68 \mathrm{c}$ & $24.91-50.56$ \\
\hline \multirow[t]{5}{*}{ Propiconazole } & Fairway & 223 & $74.96 \mathrm{a}$ & $20.79-100$ \\
\hline & Green & 84 & $79.31 \mathrm{a}$ & $37.42-100$ \\
\hline & Rough & 196 & $47.28 \mathrm{~b}$ & $21.96-100$ \\
\hline & Tee & 162 & $77.33 \mathrm{a}$ & $24.26-100$ \\
\hline & VGC & 16 & $31.25 \mathrm{c}$ & $25.62-36.73$ \\
\hline
\end{tabular}

$\mathrm{v}$ Discriminatory doses for propiconazole, iprodione, and boscalid were 0.1 , 1.0 , and $1,000 \mu \mathrm{g}$ of a.i./ml, respectively.

${ }^{w}$ Single leaf blades from individual dollar spot infection centers exhibiting characteristic dollar spot symptoms were collected from $0.93-\mathrm{m}^{2}$ areas within fairways, greens, roughs, and tees of various golf courses and a single research facility in New Jersey.

${ }^{x}$ Relative mycelial growth was determined by dividing 48 -h mean colony diameter on fungicide-amended media by mean colony diameter of isolates grown on the unamended media and multiplying by 100 .

y Means within each fungicide followed by the same letter are not statistically different at $P<0.05$ according to Fisher's protected least significant difference test.

${ }^{\mathrm{z}}$ The Vineyard Golf Cub (VGC) has never been sprayed with a synthetic fungicide, and isolates from fairways, greens, and tees served as the baseline population for sensitivity. 


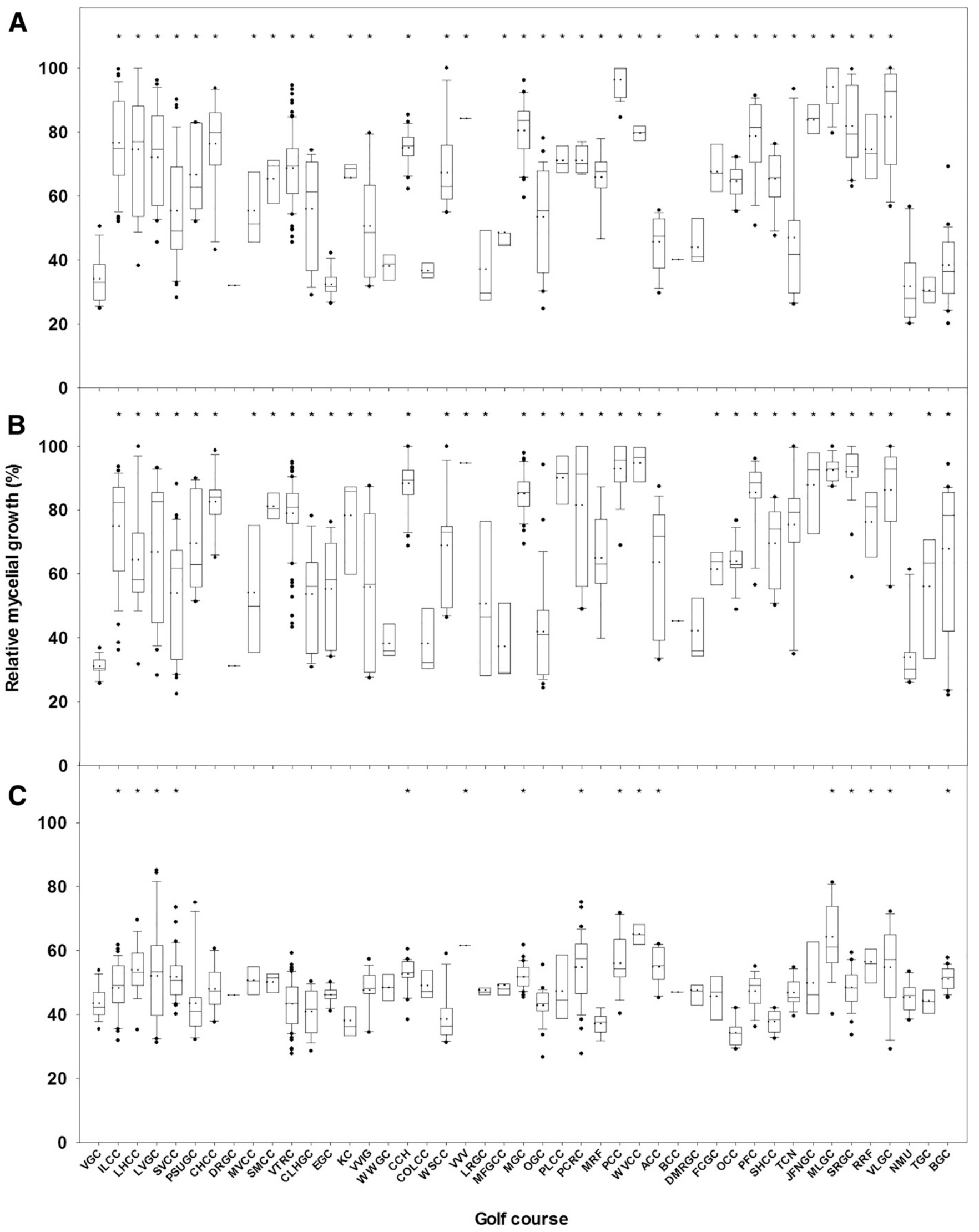

Fig. 3. Distribution of Sclerotinia homoeocarpa isolates $(n=681)$ collected from 45 different golf courses based on relative mycelial growth values when grown on iprodione (A), propiconazole (B), and boscalid (C) amended media. The upper and lower bounds of each box represent the 75 th and 25 th percentiles, respectively. The upper and lower whiskers represent the 90 th and 10 th percentiles, respectively. Median and mean relative mycelial growth values are represented by a solid black line and a dotted line, respectively. Outlier isolates are designated by a solid black dot. Golf courses indicated with an asterisk $\left({ }^{*}\right)$ exhibited reduced fungicide sensitivity when compared with the baseline population from the Vineyard Golf Club (VGC) at $P<0.05$ according to Fischer's protected least significant difference test. Golf course abbreviations are listed in Table 2. 
Mean $\mathrm{EC}_{50}$ values for VGC isolates utilized in this study were 0.77 and $0.07 \mu \mathrm{g}$ of a.i./ml for iprodione and propiconazole, respectively. These values were higher when compared with the sensitivity of a baseline population from the same golf course used in a prior study (0.28 and $0.0016 \mu \mathrm{g}$ of a.i./ml for iprodione and propiconazole, respectively) (Putman et al. 2010). The baseline sensitivity in the present study and in Putman et al. (2010) were higher when compared with the baseline population from Ohio used by Jo et al. (2006) ( 0.15 and $0.003 \mu \mathrm{g}$ of a.i./ml for iprodione and propiconazole, respectively). There are many factors that may result in discrepancies when determining baseline concentrations including methodology, assay reproducibility, and changing population dynamics over time. For example, Jo et al. (2006) used a linear regression model to determine $\mathrm{EC}_{50}$ values, whereas probit transformation analysis was used in the present study. The probit transformation is commonly used in biological dose-response studies as a technique to adjust the dosage-response curve, which allows for more accurate determination of $\mathrm{EC}_{50}$ values (Hsiang et al. 1998; Miller et al. 2002; Putman et al. 2010; Sokal and Rohlf 1981). Miller et al. (2002) examined the reproducibility of determining $\mathrm{EC}_{50}$ values based on using different in vitro methodologies. After using a modified mycelial growth assay to estimate $\mathrm{EC}_{50}$ values of two isolates previously characterized by Burpee (1997), lower EC $_{50}$ values were observed than previously reported (Miller et al. 2002). Although baseline sensitivity for propiconazole and iprodione varied among studies, the baseline population utilized in the current study was consistently among the most sensitive to the fungicides evaluated.

The baseline population in this study is composed of isolates that are from the same golf course as the baseline population used by Putman et al. (2010). Although the baseline sensitivity is higher in the

Table 2. Average relative mycelial growth of Sclerotinia homoeocarpa isolates evaluated in vitro against boscalid, iprodione, and propiconazole and percent of isolates resistant to thiophanate-methyl

\begin{tabular}{|c|c|c|c|c|c|}
\hline \multirow[b]{2}{*}{ Location } & \multirow[b]{2}{*}{$n$} & \multicolumn{3}{|c|}{ Mean relative mycelial growth ${ }^{x}$} & \multirow{2}{*}{$\frac{\text { Percent resistant }}{\text { Thiophanate-methyl }}$} \\
\hline & & Boscalidy & Iprodione & Propiconazole & \\
\hline Allegheny Country Club (ACC) & 13 & 55.03 & 45.65 & 63.74 & 8 \\
\hline Beavercreek Golf Club (BGC) & 26 & 51.55 & 39.53 & 69.94 & 77 \\
\hline Penn State University GC (PSUGC) & 10 & 43.43 & 66.66 & 69.58 & 40 \\
\hline Butler Country Club (BCC) & 2 & 47.04 & 40.23 & 45.24 & 0 \\
\hline Country Club of Harrisburg (CCH) & 20 & 52.74 & 75.13 & 88.24 & 95 \\
\hline Centre Hills Country Club (CHCC) & 10 & 47.96 & 76.37 & 82.57 & 100 \\
\hline Coatesville Country Club (CCC) & 2 & 61.59 & 84.31 & 94.69 & 100 \\
\hline Colonial Country Club (COLCC) & 5 & 49.09 & 36.63 & 38.26 & 20 \\
\hline Culbertson Hills Golf Club (CLHGC) & 14 & 54.79 & 87.89 & 81.53 & 36 \\
\hline Diamond Run Golf Club (DMRGC) & 7 & 40.92 & 56.11 & 53.75 & 14 \\
\hline Down River Golf Club (DRGC) & 4 & 47.56 & 44.00 & 42.21 & 0 \\
\hline Erie Golf Club (EGC) & 12 & 48.08 & 27.35 & 26.35 & 50 \\
\hline Fox Chapel Golf Club (FCGC) & 8 & 46.17 & 32.42 & 55.22 & 63 \\
\hline Iron Lakes Country Club (ILGC) & 39 & 45.71 & 67.64 & 61.43 & 5 \\
\hline Jack Frost National Golf Club (JFN) & 8 & 48.23 & 76.66 & 74.91 & 50 \\
\hline Kahkwa Club (KC) & 8 & 49.89 & 83.92 & 87.87 & 13 \\
\hline Ledge Rock Golf Club (LRGC) & 8 & 38.08 & 65.78 & 78.31 & 50 \\
\hline Lehigh Country Club (LHCC) & 19 & 47.56 & 37.22 & 50.69 & 47 \\
\hline Locust Valley Golf Course (LVGC) & 21 & 53.91 & 74.67 & 64.56 & 14 \\
\hline Manufacturers' Golf and CC (MFGCC) & 8 & 52.15 & 72.09 & 66.94 & 25 \\
\hline McDonald Research Farm (MRF) & 9 & 49.15 & 48.54 & 37.22 & 22 \\
\hline Merion Golf Club (MGC) & 32 & 37.17 & 65.96 & 65.04 & 23 \\
\hline Mountain Laurel Golf Club (MLGC) & 17 & 51.83 & 80.48 & 85.16 & 100 \\
\hline Mountain View Country Club (MVCC) & 5 & 64.35 & 94.20 & 92.50 & 40 \\
\hline Northern Mich. University GG (NMU) & 11 & 50.59 & 55.48 & 54.18 & 0 \\
\hline Oakmont Country Club (OCC) & 12 & 45.63 & 33.65 & 34.53 & 92 \\
\hline Overbrook Golf Club (OGC) & 28 & 34.22 & 64.62 & 63.98 & 11 \\
\hline Philadelphia Country Club (PCC) & 18 & 42.89 & 53.45 & 41.95 & 0 \\
\hline Philadelphia Cricket Club (PCRC) & 36 & 56.03 & 96.40 & 92.97 & 33 \\
\hline Pittsburgh Field Club (PFC) & 13 & 47.27 & 78.74 & 85.47 & 46 \\
\hline Plymouth Country Club (PLCC) & 4 & 47.29 & 71.07 & 90.01 & 100 \\
\hline Rutgers Research Farm (RRF) & 8 & 56.49 & 74.63 & 76.21 & 88 \\
\hline Saucon Valley Country Club (SVCC) & 37 & 51.77 & 55.45 & 54.03 & 30 \\
\hline Sewickley Heights Country Club (SHCC) & 11 & 37.83 & 65.40 & 69.57 & 45 \\
\hline Skytop Mountain Country Club (SMCC) & 6 & 50.18 & 66.01 & 81.76 & 100 \\
\hline Split Rock Golf Course (SRGC) & 26 & 48.40 & 81.92 & 92.01 & 0 \\
\hline The Club at Nevillewood (TCN) & 15 & 46.89 & 46.98 & 75.49 & 33 \\
\hline Thendara Golf Club (TGC) & 6 & 44.24 & 30.53 & 56.12 & 0 \\
\hline Valentine Turfgrass RC (VTRC) & 78 & 47.16 & 42.61 & 55.22 & 69 \\
\hline Valhalla Golf Club (VLGC) & 12 & 54.76 & 84.89 & 86.33 & 92 \\
\hline Venengo Valley Inn \& Golf (VVIG) & 17 & 48.47 & 50.99 & 59.36 & 65 \\
\hline Vineyard Golf Club (VGC) $)^{\mathrm{z}}$ & 16 & 43.67 & 33.68 & 31.25 & 0 \\
\hline West Shore Country Club (WSCC) & 11 & 38.60 & 67.36 & 68.88 & 82 \\
\hline Whispering Woods Golf Club (WWGC) & 4 & 48.36 & 38.06 & 38.25 & 25 \\
\hline Whitemarsh Valley CC (WVCC) & 5 & 65.03 & 79.67 & 94.60 & 100 \\
\hline
\end{tabular}

\footnotetext{
${ }^{\mathrm{x}}$ Relative growth was determined by dividing 48 -h mean colony diameter on fungicide-amended media by mean colony diameter of isolates grown on the nonamended media.

${ }^{\mathrm{y}}$ Isolates were screened in vitro against boscalid, iprodione, and propiconazole using the discriminatory concentrations of $1,000,1.0$, and $0.1 \mu \mathrm{g}$ of a.i./ml, respectively.

${ }^{\mathrm{z}}$ Isolates from VGC, which has never been exposed a synthetic fungicide, served as the baseline for sensitivity.
} 
present study, Putman et al. (2010) suggested the possibility of reduced fungicide sensitivity at VGC. S. homoeocarpa populations at this location may have continued to shift from sensitive to more insensitive over the past 8 years. There are many factors that may influence the development of fungicide-insensitive $S$. homoeocarpa populations other than fungicide applications alone (Latin 2011). For example, Koch et. al. (2009) observed that a fairway population from Wisconsin $(\mathrm{BH})$ received twice as many DMI fungicide applications over a 5-year period as a fairway population from Massachusetts. Despite the differences in the number of applications, the Massachusetts population exhibited higher levels of DMI insensitivity (Koch et al. 2009). It was concluded that the number of fungicide applications is not a universal predictor for fungicide resistance development (Koch et al. 2009). Many other factors such as management location, spray patterns, environmental conditions, and genetic regulation may contribute to the complex phenomenon of fungicide resistance (Latin 2011).

Owing to the lack of literature on the in vitro assessment of boscalid insensitivity, there has not been a previously reported baseline sensitivity. Mean RMGs of isolates collected from the rough ( $n=196)$, however, were similar to the baseline population used in this study. This suggests that populations obtained from VGC may serve as a representative baseline of $S$. homoeocarpa sensitivity to boscalid.

RMG was the preferred metric used in analysis for the present study because RMG is normalized and allows for equal comparison across different fungicides. Mean RMG values of the baseline population were 33.68 and 31.25 for iprodione and propiconazole, respectively. These values are similar to those previously determined using isolates from the same location (38 and 21 for iprodione and propiconazole, respectively) (Putman et al. 2010).

Results from this study support the quantitative nature of insensitivity to iprodione, propiconazole, and boscalid, as well as the qualitative nature of thiophanate-methyl resistance. Relative to our baseline population, propiconazole and iprodione insensitivity was found at high frequencies when evaluating individual isolates, golf course populations, and regions. Putman et al. (2010) found $70 \%$ of the populations evaluated were insensitive to iprodione. Jo et al.

Table 3. Relative mycelial growth of Sclerotinia homoeocarpa isolates collected from different regions and grown on potato dextrose agar amended with discriminatory concentrations of boscalid, iprodione, and propiconazole

\begin{tabular}{|c|c|c|c|c|c|c|c|}
\hline \multirow[b]{3}{*}{ Region } & \multirow[b]{3}{*}{$n$} & \multicolumn{6}{|c|}{ Relative mycelial growth $(\%)^{\mathrm{v}}$} \\
\hline & & \multicolumn{2}{|c|}{ Boscalid $^{w}$} & \multicolumn{2}{|c|}{ Iprodione $^{x}$} & \multicolumn{2}{|c|}{ Propiconazole ${ }^{y}$} \\
\hline & & Mean & Range & Mean & Range & Mean & Range \\
\hline Allentown & 116 & $51.00^{* z}$ & $31.20-85.07$ & $68.74 *$ & $28.25-100$ & $65.11 *$ & $22.34-100$ \\
\hline Central & 113 & $47.59^{*}$ & $27.84-75.00$ & $46.40^{*}$ & $19.62-93.71$ & $57.97 *$ & $20.79-98.60$ \\
\hline Erie & 55 & 44.53 & $28.57-58.18$ & $49.45^{*}$ & $26.50-79.71$ & $58.25 *$ & $27.41-95.51$ \\
\hline Harrisburg & 36 & 47.92 & $31.25-60.42$ & $67.41 *$ & $33.64-100$ & $75.38 *$ & $29.93-100$ \\
\hline New Jersey & 8 & $56.49^{*}$ & $38.24-79.86$ & $74.63^{*}$ & $58.29-90.13$ & $76.21 *$ & $48.66-95.83$ \\
\hline Kentucky & 12 & $54.76^{*}$ & $29.18-72.26$ & $84.89^{*}$ & $56.87-100$ & $86.33 *$ & $55.88-100$ \\
\hline Michigan & 11 & 45.63 & $38.24-53.45$ & 33.65 & $20.12-56.73$ & 34.53 & $25.97-61.36$ \\
\hline New York & 6 & 44.24 & $40.19-50.57$ & 30.53 & $22.87-38.87$ & $56.12 *$ & $30.45-76.31$ \\
\hline Ohio & 26 & $51.55^{*}$ & $45.23-57.83$ & 39.53 & $20.14-69.23$ & $69.94 *$ & $21.96-94.36$ \\
\hline Philadelphia & 150 & $50.58^{*}$ & $26.55-75.12$ & $74.01 *$ & $24.34-100$ & $72.13 *$ & $24.22-100$ \\
\hline Pittsburgh & 81 & 45.10 & $29.14-62.01$ & $58.59 *$ & $26.16-93.47$ & $67.69^{*}$ & $32.18-100$ \\
\hline Scranton & 51 & $53.95^{*}$ & $33.64-81.23$ & $86.33^{*}$ & $63.02-100$ & $91.52 *$ & $58.95-100$ \\
\hline VGC (baseline) & 16 & 43.67 & $35.30-53.73$ & 33.68 & $24.91-50.56$ & 31.25 & $25.62-36.73$ \\
\hline
\end{tabular}

$\mathrm{v}$ Relative mycelial growth was determined by dividing 48-h mean colony diameter on fungicide-amended media by mean colony diameter of isolates grown on the unamended media and multiplying by 100.

${ }^{w}$ The discriminatory concentration for boscalid was $1,000 \mu \mathrm{g}$ of a.i. $/ \mathrm{ml}$.

${ }^{x}$ The discriminatory concentration for iprodione was $1.0 \mu \mathrm{g}$ of a.i. $/ \mathrm{ml}$

y The discriminatory concentration for propiconazole was $0.1 \mu \mathrm{g}$ of a.i./ml.

z Means followed by an asterisk (*) indicate regions that have higher mean relative mycelial growth values when compared with isolates from the Vineyard Golf Club (VGC) at $P<0.05$ according to Fisher's protected least significant different test. VGC has never been sprayed with a synthetic fungicide and served as the baseline population for sensitivity.

Table 4. Resistance of Sclerotinia homoeocarpa isolates to thiophanate-methyl based on region

\begin{tabular}{|c|c|c|c|c|}
\hline Region $^{v}$ & Number of golf courses & Number of isolatesw & Number of locations ${ }^{x}$ & Percent resistant ${ }^{y}$ \\
\hline Allentown & 4 & 116 & 14 & 22 \\
\hline Central & 6 & 113 & 25 & 67 \\
\hline Erie & 5 & 55 & 16 & 44 \\
\hline Harrisburg & 3 & 36 & 5 & 81 \\
\hline New Jersey & 1 & 8 & 1 & 88 \\
\hline Kentucky & 1 & 12 & 4 & 91 \\
\hline Michigan & 1 & 11 & 8 & 0 \\
\hline New York & 1 & 6 & 5 & 0 \\
\hline Ohio & 1 & 26 & 11 & 77 \\
\hline Philadelphia & 10 & 150 & 22 & 23 \\
\hline Pittsburgh & 8 & 81 & 23 & 42 \\
\hline Scranton & 3 & 51 & 6 & 41 \\
\hline $\mathrm{VGC}^{\mathrm{z}}$ & 1 & 16 & 7 & 0 \\
\hline
\end{tabular}

v Geographic region where Sclerotinia homoeocarpa isolates were obtained.

${ }^{w}$ Number of $S$. homoeocarpa isolates evaluated in vitro against thiophanate-methyl.

${ }^{x}$ Number of specific $0.93-\mathrm{m}^{2}$ areas where $S$. homoeocarpa isolates were collected from golf courses within each region.

y Percentage of $S$. homoeocarpa isolates resistant to thiophanate-methyl at $1,000 \mu \mathrm{g}$ of a.i./ml concentration.

${ }^{\mathrm{z}}$ The Vineyard Golf Club (VGC) has never been sprayed with a synthetic fungicide and served as the baseline population for sensitivity. 
(2006) found $64 \%$ of golf courses evaluated had isolates insensitive to iprodione. Similarly, propiconazole insensitivity was found at 90 to $96 \%$ of the populations evaluated in previous studies (Jo et al. 2006; Putman et al. 2010). These findings are in line with previous literature and show a similar degree of propiconazole (85\%) and iprodione $(80 \%)$ insensitivity. On a golf course population basis, propiconazole insensitivity was found at $82 \%$ of golf courses, and iprodione insensitivity was found at $78 \%$ of golf courses. Insensitivity to dicarboximides may be conferred by a mutation that alters osmotic regulation in the pathogen. This factor may result in a loss of fitness in the field, making the iprodione-resistant or -insensitive isolates less competitive against sensitive wild-type isolates. Ultimately, this mechanism may be responsible for the discrepancies

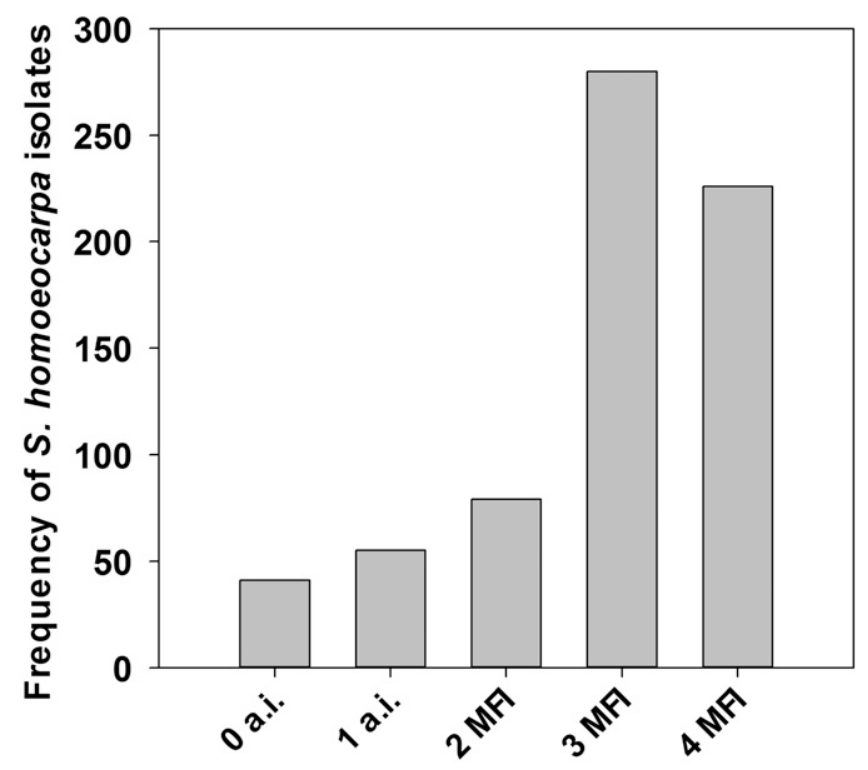

\section{Fungicide insensitivity profiles}

Fig. 4. Number of Sclerotinia homoeocarpa isolates exhibiting various resistance or insensitivity profiles to boscalid, iprodione, propiconazole, and thiophanate-methyl. Multiple fungicide insensitivity (MFI) refers to isolates that are insensitive or resistant to two or more fungicides evaluated. Fungicide insensitivity profiles indicated by 0 or 1 a.i. represent isolates that are sensitive to all active ingredients or are insensitive/resistant to a single active ingredient, respectively.
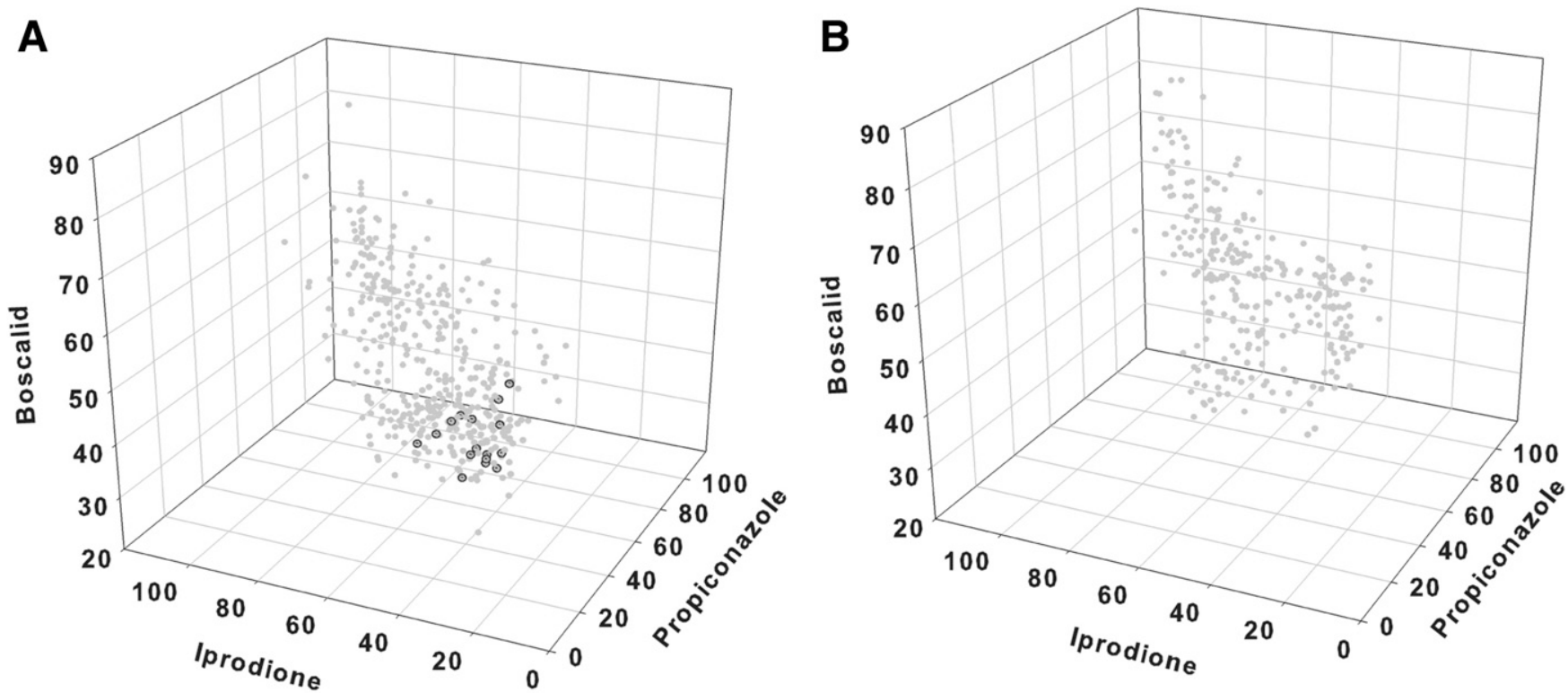

Fig. 5. Varying degrees of insensitivity of Sclerotinia homoeocarpa isolates to boscalid, iprodione, and propiconazole in which isolates were sensitive to thiophanate-methyl (A) or resistant to thiophanate-methyl (B). Isolates from the Vineyard Golf Club served as the baseline for sensitivity and are designated by a circle (O). 
population is an important component when evaluating in vitro fungicide sensitivity of $S$. homoeocarpa. The wide range of in vitro fungicide sensitivity and MFI profiles present in this study confirm the complex nature of fungicide resistance development.

\section{Acknowledgments}

We give a special thank you to the superintendents who participated in this research and to Peter Landschoot for collecting samples from the Vineyard Golf Club.

\section{Literature Cited}

Avenot, H. F., and Michailides, T. J. 2010. Process in understanding molecular mechanisms and evolution of resistance to succinate dehydrogenase inhibiting (SDHI) fungicides in phytopathogenic fungi. Crop Prot. 29: 643-651.

Avenot, H. F., Sellam, A., Karaoglanmidis, G., and Michailides, T. J. 2008. Characterization of mutations in the iron-sulfur subunit of succinate dehydrogenase correlating with boscalid resistance in Alternaria alternata from California pistachio. Phytopathology 98:736-742.

Bennett, F. T. 1937. Dollar spot of turf and its causal organism Sclerotinia homoeocarpa $\mathrm{n}$. sp. Ann. Appl. Biol. 24:236-257.

Bishop, P., Sorochan, J., Ownley, B. O., Samples, T. J., Windham, A. S., Windham, M. T., and Trigiano, R. N. 2008. Resistance of Sclerotinia homoeocarpa to iprodione, propiconazole, and thiophanate-methyl in Tennessee and Northern Mississippi. Crop Sci. 48:1615-1620.

Burpee, L. L. 1997. Control of dollar spot on creeping bentgrass caused by an isolate of Sclerotinia homoeocarpa resistant to benzimidazole and demethylase-inhibitor fungicides. Plant Dis. 81:1259-1263.

Cole, H., Taylor, B., and Duich, J. 1968. Evidence of differing tolerances to fungicides among isolates of Sclerotinia homoeocarpa. Phytopathology 58: 683-686.

Couch, H. B. 1995. Diseases of Turfgrasses, 3rd Ed. Krieger, Malabar, FL.

Detweiler, A. R., Vargas, J. M., Jr., and Danneberger, T. K. 1983. Resistance of Sclerotinia homoeocarpa to iprodione and benomyl. Plant Dis. 67:627-630.

Goldberg, C. W., and Cole, H. 1973. In vitro study of benomyl tolerance exhibited by Sclerotinia homoeocarpa. Phytopathology 63:201-202.

Golembiewski, R. C., Vargas, J. M., Jr., Jones, A. L., and Detweiler, A. R. 1995. Detection of demethylation inhibitor (DMI) resistance in Sclerotinia homoeocarpa populations. Plant Dis. 79:491-493.

Hsiang, T., Yang, L., and Barton, W. 1998. Relative virulence of isolates of Sclerotinia homoeocarpa with varying sensitivity to propiconazole. Br. Soc. Plant Pathol. 104:163-169.

Jo, Y.-K., Chang, S. W., Boehm, M., and Jung, G. 2008. Rapid development of fungicide resistance by Sclerotinia homoeocarpa on turfgrass. Phytopathology 98:1297-1304.
Jo, Y.-K., Niver, A. L., Rimelspach, J. W., and Boehm, M. J. 2006. Fungicide sensitivity of Sclerotinia homoeocarpa from golf courses in Ohio. Plant Dis. 90:807-813.

Koch, P. L., Grau, C. R., Jo, Y. K., and Jung, G. 2009. Thiophanate-methyl and propiconazole sensitivity in Sclerotinia homoeocarpa populations from golf courses in Wisconsin and Massachusetts. Plant Dis. 93:100-105.

Kretschmer, M., Leroch, M., Mosbach, A., Walker, A. S., Fillinger, S., Mernke, D., Schoonbeek, H. J., Pradier, J. M., Leroux, P., De Waard, M. A., and Hahn, M. 2009. Fungicide-driven evolution and molecular basis of multidrug resistance in field populations of the grey mould fungus Botrytis cinerea. PLoS Pathog. 5:e1000696.

Latin, R. 2011. A Practical Guide to Turfgrass Fungicides. American Phytopathological Society, St. Paul, MN.

Leroux, P., Fritz, R., Debieu, D., Albertini, C., Lanen, C., Bach, J., Gredt, M., and Chapeland, F. 2002. Mechanisms of resistance to fungicides in field strains of Botrytis cinerea. Pest Manag. Sci. 58:876-888.

Miller, G. L., Stevenson, K. L., and Burpee, L. L. 2002. Sensitivity of Sclerotinia homoeocarpa isolates to propiconazole and impact on control of dollar spot. Plant Dis. 86:1240-1246.

Ok, C. H., Popko, J. T., Jr., Campbell-Nelson, K., and Jung, G. 2011. In vitro assessment of Sclerotinia homoeocarpa resistance to fungicides and plan growth regulators. Plant Dis. 95:51-56.

Putman, A. I., Jung, G., and Kaminski, J. E. 2010. Geographic distribution of fungicide-insensitive Sclerotinia homoeocarpa isolates from golf courses in the northeastern United States. Plant Dis. 94:186-195.

Sang, H., Hulvey, J., Popko, J. T., Jr., Lopes, J., Swaminathan, A., Chang, T., and Jung, G. 2015. A pleiotropic drug resistance transporter is involved in reduced sensitivity to multiple fungicide classes in Sclerotinia homoeocarpa. Mol. Plant Pathol. 16:251-261.

Smiley, R. W., Dernoeden, P. H., and Clarke, B. B. 2005. Compendium of Turfgrass Diseases, 3rd Ed. American Phytopathological Society, St. Paul, MN.

Sokal, R. R., and Rohlf, F. J. 1981. Page 859 in: Biometry: The Principles and Practice of Statistics in Biological Research. W. H. Freeman and Co., New York, NY.

Vargas, J. M., Jr. 2005. Management of Turfgrass Diseases, 3rd Ed. Wiley, Hoboken, NJ.

Vargas, J. M., Jr., Golembiewski, R., and Detweiler, A. R. 1992. Dollar spot resistance to DMI fungicides. Golf Course Manage. 60:50-54.

Veloukas, T., Markoglou, A. N., and Karaoglanidis, G. S. 2013. Differential effect of $S d h \mathrm{~B}$ gene mutations on the sensitivity to SDHI fungicides in Botrytis cinerea. Plant Dis. 97:118-122.

Viji, G., Uddin, W., O’Neill, N. R., Mischke, S., and Saunders, J. A. 2004. Genetic diversity of Sclerotinia homoeocarpa isolates from turfgrasses from various regions in North America. Plant Dis. 88:1269-1276.

Warren, C. G., Sanders, O. L., and Cole, H. 1974. Sclerotinia homoeocarpa tolerance to benzimidazole configuration fungicides. Phytopathology 64: 1139-1142. 